\title{
Patterns of strategies in Swiss Higher Education Institutions
}

Tatiana Fumasoli and Benedetto Lepori

Centre for Organizational Research (CORe), Faculty of Economics, University of Lugano, via Buffi, 6900 Lugano, Switzerland, tatiana.fumasoli@usi.ch

This paper is published in Higher Education.

The final publication is available at http://www.springerlink.com/content/15235q226217g281/fulltext.pdf

\begin{abstract}
This paper contributes to the debate on strategic capability of academic organizations by presenting three case studies of Swiss Higher Education Institutions. Strategies are conceived as instruments by which universities manage their organizational processes and deal with their environments in order to select a portfolio of activities and find an appropriate position in the higher education system. Our findings show that strategies are at the same time a matter of intentions and actions: first, they relate to current HEI's position within the national Higher education system - and to relevant normative models - as well as to the degree of institutional autonomy. Second, even within participatory governance structures, organizational strategies appear to be initiated by the academic administrators, then substantially shaped and subscribed by academics at different stages. In this perspective, the dynamic relation of formal and informal processes holds diverse functions from making academics accept a strategy, to controlling and coordinating decentralized organizational structures.
\end{abstract}

Key words: Higher Education Institution strategy, universities as specific organizations, internal governance, institutional autonomy, higher education system

This paper benefited substantially from the comments of the anonymous reviewers assigned by Higher Education and from the insightful observations of John Usher, University of Lethbridge.

\section{Introduction}

There are some reasons why the topic of organizational strategy is increasingly relevant also for Higher Education Institutions (HEIs). First, new models of steering may grant additional institutional autonomy to universities (Ferlie et al. 2008) and thus increasingly require them to define their position in the system. Second, in the framework of New Public Management reforms, the state has been demanding some kind of 
planning, whose most concrete outcome is the strategic plan (Maassen and Potman 1990). Third, national and international competition among HEls, as well as the adoption of funding models based on results, creates pressures on HEls to differentiate by constructing their own portfolios (Bonaccorsi and Daraio 2007a). These developments call for what the business literature considers the components of an organizational strategy, namely to manage relations with environments, to define one's own position or competitive leading edge and, third, to define objectives and manage organizational action (Chandler 1990, Scott 2003).

However strategy is a controversial issue in higher education literature - as scholars have somehow avoided this topic, concentrating more on governance, organization, management and leadership. This attitude can be explained with the nature of HEls as specific organizations, whose decentralized structure as well as an unclear and ambiguous technology are supposed to render strategy difficult (Musselin 2007). At the same time, the subject of strategy has suffered a normative approach and a predominance of examples drawn from specific national contexts, like the US. On top of that, empirical studies on the nature of strategies inside HEls are rare (with significant exception of Hardy 1991, Gioia and Thomas 1996, Jarzabkowski 2008).

The objective of this paper is to examine the nature of organizational strategies in HEI focusing on two complementary dimensions: first, their development process related to the HEls internal governance and the relations among relevant actors (administrators in boards and rectorates as well as academics); second, the content of these strategies, i.e. the portfolio of activities and the envisaged HEI position in the national higher education system. The general discussion is supported with empirical findings from a small-scale case study on three Swiss higher education institutions.

The paper is organized as follows: in the next section, we present a discussion on the concept of organizational strategies, we review the current debate on strategies in HEls and we formulate our research questions. In section three, we delineate the strategic space of Swiss higher education and its recent changes, we then portray the position of our three institutions. In section four, we present our results concerning the characteristics of strategies in these organizations, as well as on the relationship between strategy and internal governance and on the shaping of portfolio and position. The last section provides some general conclusions.

\section{Strategy as (socially recognized) patterns of decisions and actions}

The literature on strategy converges on some major points (Chandler 1990; Scott 2003): strategy aims at handling environments, has a dimension of positioning, i.e., identifying one organization's competitive profile, and comprises intentions and actions at the same time. However, besides these general arguments, viewpoints on strategy differ among authors and traditions. 
A first approach conceptualizes strategy as a plan to link objectives to means (Steiner 1979), featuring a linear relationship between goals to be selected in an initial stage, means and organizational features and resources. This perspective considers strategy mainly as an organizational internal process of alignment to predefined objectives. With Porter (Porter 1980) the issue of positioning in the environments adds a new dimension by relating organizational strategic action outside its boundaries and particularly against competitors: the ability to strategize becomes thus the capability to analyze its own industry and detect the best "unique" position to achieve. A third line of research defines strategy as a pattern in a stream of decisions and actions, featuring it as a dynamic process in organizational decision making and action and not simply as an output or as a program to follow (Mintzberg and Waters 1985). These approaches focus on the dynamic relation between strategy, organizational dimensions and environment, where the achievement of strategic objectives is determined by boundary conditions such as organizational technology, institutions, actors and environments, that allow, frame and constrain strategies. As the first two conceptions of strategy relate to a more rational-hierarchical organization, the latter considers complex organizations - where coordination and control, as well as formalization, are low. Conceptually and empirically Mintzberg's framework distinguishes between intended, deliberate, realized and emergent strategies, allowing for a larger and multifaceted notion of strategy as a collective pursuit of organizational objectives (Mintzberg 1979).

The issue of intentions and actions in the framework of the debate on strategy has been raised by several authors. In fact strategy as a pattern entails the danger of identifying strategies where there is none but a sequence of coherent decisions and actions, due to antecedents unrelated to organizational goals (Gimeno 2002). MacCrimmon (MacCrimmon 1993) warns also about the ambiguity of searching strategies through patterns of decisions and actions: while direct observation may be based on researcher's incorrect assumptions, interviews only reveal perceptions of management and other actors; these observations are furthermore often biased by selective and self-serving memory, as well as possibly erroneous attribution to causal relationships. Hence a double methodology with narrative (case studies) and classificatory (typology identification) objectives is recommended (Ginsberg 1984).

Following this line of reasoning, Chaffee's interpretive model focuses on the function of strategy in providing sense to organizational stakeholders and in building institutional legitimacy and reputation, (Chaffee 1985). Thus strategy (also) makes sense retrospectively of past organizational actions, which were essentially not deliberate, and provides organizational members with meaning for future collective undertaking (Weick 1979). This aspect is likely to be fundamental for decentralized organizations like HEls, as a strategy should (also) be able to align individual action and allow sub-units coordination (e.g. faculties) within broader organizational goals in a sophisticated balance with academic freedom. 
For the purposes of this paper, we define a strategy as a pattern of decisions and actions aiming at realizing objectives that are relevant for the organization and which compose a coherent sequence developing in time and across relevant areas of activity. To be identified as a strategy, such patterns must be recognized and shared by organizational members as a collective pursuit of organizational goals. Actors' rationalization of a pattern as an organizational strategy can occur before decisions and actions take place (as in strategy formulation, for example in the strategic plan), meanwhile or afterwards, as actors rationalize organizational events in a strategic perspective.

\subsection{Strategies in higher education institutions}

The question whether universities are able to produce their own strategy is not so obvious in higher education studies. Significant part of the existing literature posits that strategy at the institutional level is not possible in complex and loosely coupled organizations such as universities (for an overview see Leslie 1996, Musselin 2007). Attempts to analyze strategies according to planning (see for ex. Keller 1983, Kotler and Murphy 1981, Duderstadt 2000) either showed that strategy is more a ceremonial act of compliance with environmental demands, or that it only partially reflects the complexity of the organizational endeavor to produce coherent actions. These led some authors to suggest that adaptive models of strategies best fit the conditions of HEl (Maassen and Potman 1990).

According to the literature, university strategies can be limited to a reactive response to environmental pressures (Oliver 1991), to a simple mechanism for resource allocation according to predefined rules in order to maintain a vulnerable internal balance (Cohen and March 1974, Baldridge 1971), or by a low degree of autonomy in managing resources (Salancik and Pfeffer 1974). Following this perspective, university nature as loosely coupled systems would lead to emergent strategies based on ad hoc responses by learning organizational units (Weick 1976, Mintzberg 1994); or by adaptation through simultaneous tracking (Leslie 1996). Developing on Mintzberg's organizational configurations and the notion of professional bureaucracy (Mintzberg 1979), Hardy (Hardy 1991) also drew attention to the relationship between structure and strategy identifying different combinations of strategy formation processes and academic specific organizational dimensions.

Considering universities as formal organizations leads to a conception of strategies as change instruments in the hands of management (Krücken and Meier 2006). Normative stances on appropriate processes of university strategy making have been also developed, like academic planning (e.g. Keller 1983, Kotler and Murphy 1981, Duderstadt 2000) as an attempt to apply rational logic to decision making about future states of the organization (Leslie 1996). Along the same line, a microeconomics model based on the concept of university as a multi product unit (Bonaccorsi and Daraio 2007b) conceives strategy as an instrument to plan organizational decision, in order to attain defined objectives with existing resource limitations and to define one's own positioning in an increasingly competitive environment. 
Finally, a discussion of the interpretive model of strategies, based on empirical evidence from the Dutch case, has been conducted by Maassen and Potman (Maassen and Potman 1990), who link strategy to university's specific organizational features and detect different types of isomorphic action; accordingly interpretive strategies would also allow universities to become legitimate with respect to stakeholders (Chaffee 1985).

This short overview on the literature shows that there are different angles to analyze strategy in higher education institutions. We therefore posit that planning, adaptation to the environment and the production of frames of reference for internal and external actors are all components of a working HEI strategy. Not only planning is required in most countries by national authorities, but one could argue that individual HEls need to identify their niche, set long-term goals and align their organizational actions (Bonaccorsi and Daraio 2007a). At the same time, HEl are open organizations keeping close ties with the environment and, especially, subject to substantial influence from State and policy actors; moreover, higher education institutions are too decentralized to easily allow for long-term strategic planning. Finally, the level of autonomy of the academic understructure would indicate that constructing shared frames of reference and motivating individual's behavior is more important than command and control, making a strong case for interpretive strategies.

\subsection{Mapping patterns of decisions and actions}

The first objective of this paper will be to map the existing strategies in the three case studies considered for a sufficiently long period to allow for change, namely twelve years from 1996 and 2008, a period which corresponds to three legislature terms of office and covers a phase of major changes in Swiss Higher Education. Mapping strategies and their changes will then mean to analyze organizational decisions, to look for coherent patterns and to relate them to the main organizational goals.

Besides a general analysis of major organizational events and decisions, we focus on five major areas of activities (see for ex. Bonaccorsi and Daraio 2007c). First, internal structures such as governance bodies responsible for decision-making, distribution of competences, formalized procedures. Then two areas representing HEls core activities: education, whereby we look the organization of curricula and research. The last two sectors relate to resources: finances, which imply relations with the state and other donors as well as, internally, human resources policy, focusing on professoriate.

We look at strategies in these areas according to four descriptors: patterns of organizational decisions and actions, events in the environments, main actors, locus of strategy making. We expect to find out different degrees of coherence within patterns, as well as different levels of interdependence among strategic areas. Data collection has been organized in two phases. Firstly, we performed a comprehensive documentary analysis: legal and policy-making documents - university acts at cantonal and federal level, national 
strategic plans, rectors' conference policy documents -, furthermore parliamentary sessions records in order to compare what we found with the political debate and identify relevant issues and events that may not have been explicit in other documents. As of internal university documents we gathered all strategic plans and reports - inclusive yearly reports. Additionally, we looked at university board meeting agendas and, when possible, at the minutes of meetings, as well as press communiqués and any relevant information on university websites. We used data on budgets, human resources, students, programs etc. elaborated by Swiss Federal Statistical Office. This documentary analysis allowed us to detect on one side patterns of decisions and actions and external events for the period selected, on the other side to confront formal internal governance and strategy making processes, so that issues relating to tensions and conflicts could be detected, e.g. when the parliament re-discusses contracts of performances, annual budgets or when decisions taken in a first stage are not carried out over time. This method allowed us to go at the interviews by having identified key actors - who may not appear in organigrams - some (additional) issues to be clarified (e.g. compromises eventually found informally by specific groups of actors). The interviews were semi-structured and helped investigating the main topics discussed above: strategy making according to governance and actors configuration, strategy content according to the HEl's portfolio and positioning within the higher education system. The interviews were face-to-face and conducted usually in interviewees' offices for an average time of one hour and a half. We interviewed 41 persons: 16 academic administrators (members of university boards and rectorates), 28 academics (mainly full professors representing the most important faculties) and 7 policy makers (top civil servants in charge of higher education for each canton and at federal level). The number of the interviewees doesn't correspond exactly to a single case, as many of them, between 1996 and 2008, have been professionally involved in different positions, actually spanning over the three sectors mentioned. Of 28 academics interviewed, 9 had been deans. Another important criteria for selecting the academics was their reputation for being senior, well reputed professors critical to the institutional strategy of their university, as we wanted to observe how different opinions on strategy were considered. Interviews had two major objectives: validating findings from documents, as well as raising new issues, and looking to the (retrospective) interpretation by the actors of the strategic meaning of the observed patterns and of their position in the processes.

\subsection{Actors and processes of strategy making}

Our second objective concerns the analysis of the process of development and implementation of strategies and the role of organizational actors. Traditionally, higher education institutions have been considered as decentralized organizations with strong autonomy of the academic understructure (see for ex. "organized anarchies" Cohen et al. 1972) and thus it was assumed that internal governance was mostly based on shared decision-making processes where central administration has limited leeway to steer the organizational activities. However, in the last decades there has been a movement towards reinforcing the 
position of rectorate and other governing bodies, limiting the power of the academic understructure, as well as the control of the State on organizational decisions (Amaral et al. 2002); differences between national systems and individual organizations are however large (see Fumasoli 2008a for the Swiss case).

We thus consider that besides the degree of autonomy from the State, the internal governance structure and the internal distribution of power are likely to strongly influence the processes of strategy making within universities; beyond looking at the degree of centralization and the power of governing bodies the kind of organizational decisions they can control -, it is relevant also to look to conflicts between actors and to conditions for the creation of a stable advocacy coalition able to develop and implement an organizational strategy and, especially, to share its basic frames of reference and goals (Sabatier 1987). Following Jarzabkowski 2008 we also consider that strategy making processes can be effectively studied in terms of social dynamics attended by diverse actors.

Processes of strategic development and implementation are a final issue of inquiry, since they are likely also to impact on the possibility and content of organizational strategies (see for ex. Dill 1996) and thus one should focus also on actors which control these processes, on external constraints (for example from State regulations) and on how these processes are designed. In the case of $\mathrm{HEl}$, we expected to find a variable balance between informal processes of decision and consensus-building - based on personal contacts within an open setting - and formal processes where decisions are taken by the responsible body and thus legitimated officially. In this respect, we specifically look to the varying relationship between processes of strategic planning - which are in most cases mandatory requirements to $\mathrm{HEI}$ - and strategies in the broader meaning we have adopted here.

\subsection{Shaping portfolio and position between normative and goal oriented attitudes}

The third objective of the paper is to look to strategies from the perspective of their content, thus investigating the portfolio of activities on which the academic organization has to focus its main efforts, as well as the position in the higher education system, effectively looking to relationship between the organization and its environment.

Strategies content can be analyzed following different dimensions (see the distinction between arenas, vehicles and differentiators in Hambrick, D. and Friedrickson, W. 2001): portfolio of activities - the choice of educational domains, the type of programs, the focus of research - the relationships with other institutional actors - for example collaborations and strategic alliances with other HEls, but also linkages with State, funding agencies and external stakeholders - and, finally, the choice of the models assumed to aspire or to emulate, e.g. large, comprehensive school with many well-regarded faculties in sciences and humanities, technical school with expertise in engineering and science, etc. 
Pressures from public authorities requiring that HEI have a clearer and more explicit focus, competitive funding schemes which promote direct competition between HEI (e.g. for research funding) and the differentiation of social demands for higher education make the issue of positioning increasingly relevant (see for example Bonaccorsi and Daraio 2007a), as it will emerge also from our empirical analysis.

In the strategy literature, the issue of positioning has been mostly related to Porter approach to competitive advantage, where executives should choose between different strategic options (see generic strategies; Porter 1996) based on in-depth industry analysis and examination of own strengths and weaknesses, as well as of the opportunities and threats a company faces (see also Rivkin 2001, Siggelkov 2002, for a comparison with leverage and opportunity strategic logics Bingham, C. and Eisenhardt K. 2008). While Porter's call to differentiate and carve out its own niche (Porter 1980; Porter 1996) as a central function of strategies is relevant also for HEls, one should not disregard the complexities of the notion of positioning in higher education. First, while Porter's approach is prescriptive and based on a rational process, the literature converges that HEl strategies have a strong adaptive component, related both to organizational decentralization and unpredictability of the environment (see for ex. Leslie 1996). Second, ambiguity in the technology and loose coupling make problematic for central administrators to evaluate the competitive position in educational and research markets; instead, strategic choices could be also based on the ability of institutional units to provide critical resources like third-party funds or students as predicted by resource-dependency theory (Salancik and Pfeffer 1974). Third, for highly institutionalized institutions like HEl achieving legitimacy and reputation might be as important as achieving competitive edge in markets for resources acquisition and thus strategy might explicitly want to focus on this dimension.

We also advance the hypothesis that positioning choices are likely to be different depending on the characteristics of each institution. Large and/or highly reputed research universities might find their position less threatened and could limit themselves to follow a consolidation strategy, while smaller institutions might find themselves in a more unstable position especially if the environment becomes more competitive; the success of new institutions will strongly depend on finding a suitable niche, but their strategic options are likely to be less limited by historical heritage. Institutions focused on domains loosing of importance - for example in the student's choices or in political priorities for research - will also be more subject to pressure to change than those sitting in growing domains. At the same time, organizational inertia is a relevant feature of $\mathrm{HEl}$, for political and historical reasons, but also because of the costs to entry into new domains, of the rigidity of the personnel structure and the difficulty of hiring people in domains where reputation has not been already achieved. Opportunities to restructure the portfolio are thus likely to be dependent on local situations which strongly reduce their (economic and reputational) costs. 
This process is likely to depend on the structure of the strategic space, including the size of the system, specialization patterns, the set of competitors, the incentive system through public funding, as well as institutional norms - defining what an higher education institution is supposed to do in order to be legitimated - regulations, for example concerning offer of new curricula and their accreditation, and (varying degrees of) State intervention, for example relating to the portfolio of educational offer and the choice of scientific domains. Overall, system-level differences between countries in the balance between hierarchization and differentiation are likely to strongly impact on the available options especially for those HEI which cannot aspire to climb the ladder of the best reputed institutions (Bleiklie 2008).

\section{Characterizing the strategic space of Swiss higher education}

Today's Swiss higher education is composed by the two Federal Institutes of Technology (FIT) by ten Cantonal universities and seven universities of applied sciences (UAS). All these institutions deliver three years bachelor and two-year master degrees, while doctorates are not granted by UAS, which are oriented towards professional education and applied research. The system is rather decentralized and small scale: the largest university only slightly exceeds $20^{\prime} 000$ students, while many HEls are below $10^{\prime} 000$ and thus would qualify as small institutions in international comparison. Of the ten Cantonal universities, seven are broadly generalist covering most scientific domains, while three of them are specialized in a few fields; FIT's cover only natural sciences and technology, while UAS are nowadays covering most domains in professional education. A comparatively high endowment of financial resources and personnel and the very strong role of $\mathrm{HEl}$ in research, with Swiss universities ranking in the best places in Europe for their research performance, are further relevant features (Lepori 2007).

At the institutional level, Swiss higher education is characterized by two main divides: the division of competences between Confederation and Cantons and the binary divide between universities and FITs on one side, UAS on the other side. The Confederation is responsible for the two Federal Institutes of technology, while Cantons have almost sovereign competence on their Cantonal universities; for Universities of Applied Sciences the Confederation has a framework competence, but the institutions themselves are managed by the Cantons. The creation of UAS in 1997 included a large part of professional tertiary education in higher education, but with a clear separation from universities: UAS are ruled by a specific law and, at the federal level, managed by the ministry of economic affairs (while universities and FIT are under the competence of the ministry of home affairs). Curricula, careers structure and funding were from the beginning subject to specific rules, while the UAS act provided also for differentiation of their research mandate towards applied research and collaboration with small and medium enterprises (Lepori 2008). 
This setting historically implied a strong limitation of strategic autonomy of most HEl, whose broad positioning was basically defined by law and by the responsible authority, with Cantons holding a strong control on their universities; the Swiss system has thus been characterized as a mix of bureaucratic control from the State concerning finances and administration and a wide autonomy of the academic understructure for research and education; both drove to a weak position of central organizational bodies and to a lack of strategic capability of the organizations themselves (Lepori and Fumasoli 2008).

\subsection{From rigidity to soft competition}

However, in recent years this picture has evolved (Lepori and Fumasoli 2008). Firstly, with the creation of the Universities of Applied Sciences the perimeter of Swiss HEI has been significantly enlarged; overlaps between UAS and universities are rapidly emerging, especially as a consequence of the introduction of the Bologna model. Secondly, both at the federal level and in most Cantons, reforms brought more autonomy to universities and FIT and strengthened the role of rectors and presidents - yet at different degrees from organization to organization (Fumasoli 2008a); especially the two FITs profited of this leeway (and from a generous financial endowment) to profile themselves as leading research universities internationally. Thirdly, some competition in funding has been introduced in core funding and through the increase of project funding for research. However, competition has been moderated by the relatively large share of core funding and the explicit promoting of inter-institutional cooperation and thus concentration and stratification of the system has been by large avoided; what is taking place is an implicit, self-agreed and loosely steered definition of a specific portfolio for each HEI through mutual arrangements (rather than through direct State intervention).

These developments go towards creating a single space of higher education in Switzerland, as envisaged by the new higher education act which should entry into force in 2012 and thus require from $\mathrm{HEl}$ an effort to define their position and consequently select their priorities; however, the degree of pressure is highly variable between individual organizations and the governance regulatory framework limits rather strongly their freedom. At the same time, HEls are so well endowed of resources that pressure is in most cases (but not in all of them) moderate. Finally, since the reform of legal acts started at the beginning of the nineties, all universities have been required to produce strategic plans and profile themselves in the academic market (Fumasoli 2008b). These plans are consolidated by the rectors' conference in a bottom-up national planning. For the UAS sector, the approach is more directive since Confederation and Cantons jointly develop a masterplan providing directives and financial guidelines to all UAS.

\subsection{Three diverse case studies}

Our three case studies include organizations that, for different reasons, have been required to find a (new) position in the system. They are all three small size institutions (less than 5'000 students), geographically peripheral and situated in cantons that are not financially powerful. One is specialized, one is generalist 10 
(though without medicine) and the UAS is growing by integration of sectors at a pace dictated by Bern to all its competitors. For all the financial sustainability - and therefore their relation with canton and confederation - is a crucial issue.

Table 1. General description of the case studies

\begin{tabular}{|c|c|c|c|c|c|c|c|c|c|}
\hline Name & birth & type & mission & $\begin{array}{l}\text { Faculties/ } \\
\text { departments }\end{array}$ & $\begin{array}{c}\text { Total } \\
\text { expenditures } \\
\text { SFR mio } 2007\end{array}$ & $\begin{array}{c}\text { Research } \\
\text { expenditur } \\
\text { es SFR mio } \\
2007 \\
\end{array}$ & $\begin{array}{l}\text { Students } \\
2008\end{array}$ & $\begin{array}{l}\text { Staff } \\
\text { FTU } \\
2008\end{array}$ & $\begin{array}{c}\text { PhD } \\
\text { Students } \\
2008\end{array}$ \\
\hline $\begin{array}{l}\text { Università della } \\
\text { Svizzera italiana }\end{array}$ & 1996 & $\begin{array}{l}\text { cantonal } \\
\text { university }\end{array}$ & $\begin{array}{l}\text { Teaching, } \\
\text { research } \\
\text { (mainly basic) } \\
\text { Some services }\end{array}$ & $\begin{array}{l}\text { Communication sciences } \\
\text { Economics } \\
\text { Architecture } \\
\text { Informatics }\end{array}$ & 69.5 & 20.2 & 2486 & 444 & 187 \\
\hline $\begin{array}{l}\text { Université de } \\
\text { Neuchâtel }\end{array}$ & 1909 & $\begin{array}{l}\text { cantonal } \\
\text { university }\end{array}$ & $\begin{array}{l}\text { Teaching and } \\
\text { basic research }\end{array}$ & $\begin{array}{l}\text { Social sciences and } \\
\text { Humanities } \\
\text { Economics } \\
\text { Law } \\
\text { Natural and technical } \\
\text { sciences }\end{array}$ & 146.6 & 89.4 & 3826 & 817 & 568 \\
\hline $\begin{array}{l}\text { Scuola } \\
\text { universitaria } \\
\text { professionale } \\
\text { della Svizzera } \\
\text { italiana }\end{array}$ & 1997 & $\begin{array}{l}\text { University } \\
\text { of applied } \\
\text { sciences }\end{array}$ & $\begin{array}{l}\text { Professional } \\
\text { and } \\
\text { continuous } \\
\text { education, } \\
\text { applied } \\
\text { research, } \\
\text { services }\end{array}$ & $\begin{array}{l}\text { Technical disciplines } \\
\text { Healthcare } \\
\text { Social work and } \\
\text { economics } \\
\text { Innovation technologies } \\
\text { Teacher Education } \\
\text { Music } \\
\text { Theater } \\
\text { Distance Education }\end{array}$ & 62.9 & 12 & 2352 & 429 & -- \\
\hline
\end{tabular}

Data source: Swiss Federal Statistical Office.

Our first case portrays a small, specialized university created in 1996 and growing rapidly in terms of students and research activities. The main challenge is to develop the institution and to define its position in the Swiss higher education; this in a normative environment where to be considered as a university an institution needs to develop strong research activities and at least some domains of international excellence (especially in sciences). Documentary analysis and interviews show a remarkable coherence in pursuing this objective, which has been achieved in the late nineties through the official recognition by the Confederation, but more recently thanks to a rapid development of research activities and in the acquisition of competitive project funding; the normative model of Swiss universities built thus a strong framework for the organizational development. Not surprisingly, achieving legitimacy is also critical for getting the resources required for organizational growth.

The second case concerns a small century old generalist university exposed to severe pressure from the environment in order to reduce costs and attract resources. Both the size of the university - being the smallest generalist university in Switzerland and thus with an insufficient number of students to support its excellent, but cost-intensive science department- and of the host Canton - with correspondingly limited financial resources, but also mostly regional ambitions - imply a difficult positioning in the Swiss landscape. In fact this HEl, without the size and the prestige of the large universities, can't profit either of the advantages (in terms of costs and flexibility) of the niche strategy of the smaller ones. 
A university of applied sciences is our third case study: it was built clustering existing upper secondary and tertiary schools, as well as private and public research institutes and this process has continued until today. Thus, the organization had to face three major challenges: how to build an organizational structure and to reinforce its autonomy from a basis constituted by schools which were part of the public administration and are located in different places; how to master the expansion and the increasing diversity of subject domains, ranging from technology to social work and arts, as well as the organizational cultures of the merged schools; finally, how to develop an (applied) research activity throughout the whole organization, starting in most case from schools with no research tradition.

\section{Organizational strategies in three Swiss universities: mapping diversity}

Our three case studies display rather clear patterns which allow to identify different strategies during the considered period. We provide in the first three sections an overview of these patterns for each institutions, while we develop more synthetically the analysis of processes and contents in the last two sections.

\section{Insert Table 2: Summary of strategic actions according to main activities}

\subsection{USI: a progressive approach to the construction of a new university}

Our first case study displays a remarkable coherence driven by the main goal of establishing a new institution recognized in the national system, but at the same time an adaptive and progressive approach in developing its components. This drives to the identification of two distinct strategies: the first strategy (1996-2003) was devoted to national legitimacy and was centered on educational attainments - as in Switzerland block grants are primarily based on the number of students -, while the second strategy (20042008) aimed at constructing international reputation by strengthening research activities. The creation of the Faculty of informatics in 2004 represents a turning point, being the experiment where new policies concerning research and human resources were successfully introduced and then diffused to other domains.

Until 2003, teaching activities overcame any other organizational action: professors were directly employed through personal networking by executives and academics in order to respond to the high numbers of student enrolments. This faculty was in general regionally well reputed, middle-aged, non-resident and held already a chair, mostly in cross-border Northern Italy and other Swiss universities. The rate of external teachers compared to internal professors was extremely high, to the point that the two external evaluations conducted by federal authorities solicited a rebalancing according to Swiss academic standards. 
Curricula were rapidly developed with a high degree of innovation going from three through the introduction of seven areas of specialization up to three bachelors, eight majors, while masters were fourteen by 2004. This urge for acting in accordance with the teaching mission is also expressed in a pioneering behavior with respect to environmental changes, as USI was the first Swiss university to introduce the Bologna model in 2001. Patterns of actions started to shift as, from 2002, central administrators began to think on how to expand further the university: on one side they framed the option of a fourth faculty, responding to the purpose to establish a more complete higher education institution and to establish what was perceived as the missing faculty of sciences. Meanwhile, other attempts were made to foster research, creating multidisciplinary institutes outside the faculties; however these experiments proved to be much less successful than expected and were abandoned.

The faculty of informatics represented a far reaching attempt to develop hard sciences, although in a light version. This strategy was reflected in new patterns in human resources policy: the faculty was made mainly of assistant professors hired with a tenure track position, the graduate education sector was larger than the undergraduate and the staff was far more international than in the other faculties. This changes reverberated across USI, on parallel with a steady growth of the number of professors from 15 to 98 FTU, also the rate of internal resident professors augmented from a minimum of $28 \%$ in 2000 to $50 \%$ in 2008 . In 2006, the second president came into office explicitly endorsing the cause of international excellence, by constantly declaring it publicly and systematically intervening into nomination procedures and coordinating evaluations of units. The consequences at the human resources level were significant: all nomination procedures were systematized according to international peer review standards, institutes with modest research output were reorganized or even closed. The profile of professors also rapidly changed from a solely teaching dimension to integrate proven or potential research capabilities. By the end of 2008 , while students numbers stabilized, the outcomes of this new pattern of actions was observable: the competitive funding for research reached $13 \%$ of total budget, increasing $65 \%$ from 2005 , and new projects of expansion in hard sciences went underway.

\subsection{Neuchâtel: an old balance under threat}

The university of Neuchâtel could be considered as a case of strategy incoherence, where, on one side, processes eventually collapsed for the conflicts arisen, while, on the other side, the consistent application of strategic decisions was slowed and even stopped by divergent actors positions and rapid changes, particularly in the legal framework. Broadly speaking we can identify two periods, a first one where the university tried to maintain its traditional profile (1996-2001), a second characterized by a far-reaching and highly contrasted attempt to restructure the portfolio (2002-2008).

In 1996, the Canton puts in place a governance reform through a new university act which was supposed to foster strategic capability by means of a block grant and a strengthened rectorate. However, the university 
responded only partially to these demands: except for establishing some coordination with neighbor universities on educational programs, it didn't take any major action in selecting its core research activities. On the contrary, it continued to obtain a yearly linear increasing budget, based on internal balances and traditional modes of expenditure according to faculties, where the faculty of sciences was spending the most for its research activities and the faculty of human and social sciences hosted large numbers of students. In fact, patterns of coherence within the organization weakened: on one side the cantonal block grant increased between 3\% and 8\% p.a. from 1996 to 2001, reflecting a linear augmentation of human resources, while the number of students was stagnating. The number of professors hired was neither reflecting the educational needs, as the faculty of sciences augmented $11 \%$ its full professors, while at humanities only 7\% between 1996 and 2001.

In 2002, a new act modified in depth the internal governance and provided the rector with extended powers. The university management started to discuss options for restructuring, while also the reorganization of research activities was considered, even if only in the form of synergies with other HEIs. Meanwhile, the usual 4-year rector's permanence was interrupted by a interim period, as the new act required different appointing procedures to be fulfilled. Moreover, a series of new events in the environment made the situation deteriorate, like competition for students by the newly created UAS and a stronger orientation of federal funding to numbers of students and research output. Hence the university saw its leeway getting increasingly smaller and its capability to respond in terms of available resources and timing more and more constrained, while external political pressure was growing and the Canton claimed against an unsustainable financial situation.

The new rector, arrived in 2004 from another Swiss university, rapidly provided a new strategic plan, proposing to give priority on disciplines with large numbers of students and to concentrate on selected poles of excellence in research (like plant biology and micro-technique). New professorial positions were planned accordingly, while suppression of chairs with few students were also arranged. In the perspective of the human resources policy, besides an accurate timetable for chair planning, another sensitive issue was challenged, when the role of the intermediate corps got under pressure and the existence of a high number of year long positions was questioned, as assistant professor positions were planned to enhance research and $\mathrm{PhD}$ assistants were considered more appropriate for cost and flexibility reasons. Although this shake off strategy was formally accepted by the university council, as well as by the government and the parliament, the institution continued to remain under pressure when external demands and (new) resource constrains obliged the rector to delay a certain number of planned appointments, while the canton decreased its block grant (from SFR 45 millions in 2002 to SFR 42 millions in 2006). At the beginning of 2007, only two years from its adoption, one of the main axes of the university strategy (focus on micro- 
technique) was abandoned, as the government announced the transfer of this institute to the federal institute of technology in Lausanne.

The third strategic phase saw another ad interim rectorate continuing the downsizing of the faculty of science, in particular by transferring geology and particle physics to other Swiss universities, until a new rector, coming from within the university academic community was in place by the end of 2008.

\subsection{SUPSI: structuring by centralizing and decentralizing}

In our third case study two strategic periods can be identified, a first cycle where the main objective was to shape the organization (1997-2002) and a second oriented to dynamizing the organization (2003-2008) in order to support its expansion and positioning in the Swiss system. This HEI was born through the UAS act in 1997 by unifying four secondary schools and three research institutes previously part of the cantonal administration. Hence, the first period was dominated by the need to merge these schools in a single institution and to achieve a joint understanding of its mission, as well as to develop a common system of rules. Federal interventions supported this process, especially concerning education where curricula had to be accredited and reexamined regularly by federal authorities, thus following stricter requirements as of contents, organization and timing, and bringing stronger uniformity across the whole institution.

Moreover SUPSI acted from the beginning in order to seek a strategic balance between education and research activities, since these developed quite rapidly, thanks to the already existing institutes of computer integrated manufacturing and earth sciences and the integration of an institute of artificial intelligence in 1999. In 2002, research accounted for about 30\% of the total budget, the highest share of all Swiss UAS, however stronger competition by other UAS led to a stagnation of research towards the end of this period.

However, the main priority, was the reorganization of the internal structure, personnel management and logistics. Each integrated school had its own staff employed with a different legal framework (going from public servant statute to specific public administration arrangements), and the central administrators were forced to create a new contract policy and to manage transition, while formally limited autonomy in modifying working conditions, given the impact of cantonal regulations. The high number of changes at the heads of departments and institutes between 1997 and 2003 (practically all of them had their head changed at least once) shows that the central administration was able to make substitutions in this layer of management to carry out its strategy and reorganize the structure. Moreover, the institution managed to concentrate its activities in just two sites from the four at the beginning.

In this context, the second strategic cycle started with a new executive team appointed, which immediately conducted a major restructuring of the internal governance, transforming the school centralized structure into a vertical "multidivisional" organization centered on an executive board composed by one chief 
executive and the directors of departments. While keeping central control on organizational strategy, this reorganization provided departments with more autonomy concerning educational and research activities and thus promoted stronger bottom-up dynamics; research activities started to grow and to differentiate and new research centers were created - four of them being recognized as research institutes towards the end of this period. Finally, a research strategy was established by an ad hoc committee of representatives of the different departments, in order to coordinate the highly differentiated research activities and to promote cooperation between domains. In this respect, an internal fund to foster interdisciplinary research through regular calls was set up.

Building on the structures developed in the first phase, SUPSI was also able to manage successfully the (nationally politically decided) integration of new sectors; the health care schools, a music academy and a theater school were integrated in 2006, while the integration of the public teacher education was decided in 2008. An expansion strategy outside the region was also launched with the integration with a distance education school situated in another Canton, trying to overcome the small size of the regional basin. The drawback of this policy was however an increasingly complexity of the internal governance.

This period has also seen a rather systematic establishment of procedures, internal directives and personnel regulations. On one side, the pressure coming from trade unions for a better setting, eventually turned into a new regulation standardizing working conditions. On the other side, some general regulations for the specific professional profiles were put in place: the statutes of teacher-researcher and teacherprofessional were further detailed as well as some criteria for professoriate.

\subsection{Dealing with the balance between centralization and subscription}

As we consider strategy as a pattern of coherent organizational decisions and actions across relevant activity areas, we (also) imply that strategies can be deliberate (usually formalized through plans and planning processes) and emergent (adaptive and recognized ex post). This allows us to observe how strategies form, on one side initiated by the academic administrators - with the support of public funding authorities, on the other side are concretely integrated by bottom-up input from the members of the academic profession. This process is very subtle, as a balance must be found between defining general organizational goals and incorporating specific content relating to functions pertaining to the academic profession. In fact, administrators in university boards or in rectorate strategically feature functions such as finances, structure, relations with funding authorities and sponsors, while the key functions of teaching and research are featured by faculties. As this core technology is unclear and ambiguous (Musselin 2007), only academics have the capability to propose and carry out specific change on teaching offer or research activities. The inclusion of such contents in the strategy is the object of negotiations in formal avenues as well as in informal meetings, as we describe hereafter. Moreover, strategy making undergoes constant internal experimentation and selection processes in order to produce a consistent and shared strategy (see 
for ex. Burgelman's evolutionary model on intraorganizational ecology strategy making (1991) and Lovas and Ghoshal 2000 on the role of executives in guiding organizational evolution). The complexity of these processes inheres also a correct assessment of the balance of power among faculties: if some strategic decisions can be only taken by the administrators (e.g. opening of a new faculty), these have to be get accepted and shared under given faculties' power positions.

In all our cases studies strategies are elaborated by a small group of academic administrators; at the same time, strategies could unfold beyond the planning stage only if subscription of the academic understructure was achieved and, at the same time, central authorities were able to selectively integrate bottom-up developments in the organizational strategy, in order also to exploit unforeseen opportunities.

USI addressed this issue thanks to a strong centralization of power, a high degree of autonomy from the Canton and a dense network of informal contacts within the organization. The university council unifies the political, strategic and executive layers; it is composed by external members, political representatives, deans and the executive president, that also chairs it, while no academic senate has ever existed. This configuration makes the prerogatives of the president - and of the secretary general, also in charge for the budget - extremely wide ranging. Beyond deciding on the creation of new departments, appointing the members of the council and setting the level of block grant contribution, the Canton delegated all other decisions to the council (Fumasoli 2008a).

In this context, strategic plans are conceived in a first stage by academic administrators, and, in a second phase, deans are involved in the discussion and invited to contribute, and finally they are presented for adoption at the council. On the other side, academic administrators manage and adjust the strategy in order to foster bottom up initiatives, which are aligned to overarching goals - e.g. providing support for research activities perceived as promising and with critical mass - and to frustrate or censor undesirable developments - e.g. opening for specific faculty positions or new programs; hence centralization allows for adaptive elements and trial and error processes, while keeping at the same time coherence in the basic strategic objectives. The strong position of the academic administrators in setting the council agenda allows emerging strategies to be discussed and legitimated in the council also outside formal strategic processes. Subscription to organizational strategy by other organizational members is obtained through means typical for a young and small organization: strong leadership of the founding fathers - the first generation of academic administrators is still by large in its office - and coherence in their internal and external communication; centralization of authority and power especially concerning budget; a dense web of informal contacts and personnel exchanges, which allows central authority to explain strategy, to achieve subscription, to manage compromises and, finally, to integrate emerging ideas. The University of Lugano represents well this compromise between top-down decisions (new faculty of informatics in 2004) and 
search for widespread subscription through intensive personal contacts between the rectorate and the academics.

Neuchâtel displays the fragility of governance reforms intended to promote strategy in the context of lasting autonomy of the academic understructure and where the Canton keeps strong intervention power. Thus, the 1996 reform granted the rectorate some additional powers, in particular concerning the management of budget, but left untouched the existing bicephalus governance based on late 60ies claims for participatory and democratic mechanisms (i.e. besides the rectorate, a council made up of representatives of the academic community and a board of trustees). This configuration made the role of the rector difficult as reconciling diverse positions emanating from different and equal bodies was not easy and thus existing patterns by large continued.

A second intervention of the Canton in 2002 created a semi-presidential regime, where the new rector, appointed by the cantonal government and called from outside, was directly in charge of the strategy, of appointing his team members, hiring personnel except for academics. Only three months upon his arrival, a new strategic plan was prepared and rapidly approved by the council and by the government. Nevertheless, while formal procedures were respected and agreement was achieved, within the academic community restlessness was growing against a rector perceived as too much directive.

The isolation in which the rectorate worked proved not to be viable as soon as major disagreement with the Canton rose. In fact, as the government decided univocally to transfer the expensive micro-technique institute, a brief, intense and public conflict was initiated by the rector against what he considered a strategically inconsequent move, eventually stopped by the cantonal government. This case study is typical of the dilemma of university steering bodies in a regulatory context characterized by strong intervention of the cantonal authorities in decision-making processes and, at the same time, by weak institutional affiliation of academics. This situation implies the difficulty of creating a sufficiently strong advocacy coalition around a strategy which would allow to implement a substantial repositioning. The balance of power of faculties frame the possible strategic options: in this sense as the rectorate was not able to take into account the different powerful groups internally - the faculty of science - and externally - the cantonal government - and convince them on their strategy.

Finally, the university of applied sciences used a different approach based on its stronger bureaucratic culture, but also adapted to its focus on professional education and applied research where hierarchical structures are more acceptable than in the academia. A robustly hierarchical structure centered on a strong executive board - where most of the strategic decisions are taken - represents the skeleton of this governance model.

The first model was based on strong of top-down planning from the board and on an almost complete separation between the board and the department managers; while it was conductive to shaping the 18 
institution and keeping it at arm's length from the Canton, it proved to be too heavy and led to increasing conflicts between board and organizational subunits, thus de facto reducing dynamics and responsiveness to external changes.

In the second model the board was composed by the head of departments and was chaired by a strong administrator with executive powers. The delegation of competences to departments produced a multiplication of responsibilities, as every department, and even every unit within, was in charge of all four missions, i.e. education, continuous education, applied research and services. This model was conductive to stronger bottom-up dynamics, while the board took the responsibility for keeping strategic coherence at the organizational level, especially through the management of the budget and logistics, as well as for managing the interfaces between departments. This was possible only with excellent managers at the head of the departments, who could push upwards information and decisions to the director and council, and, more importantly, who can coordinate all activities below. With the further expansion of the school - with the size of the board increasing also from four to eight persons - it is coming to its limitations both concerning collegial decision-making at the board level and the workload of the heads of departments.

Human resources policy and especially planning of the chairs and nomination of the professor emerge from our case studies as a central issue in HEI strategies, concerning contents - the choice of the profile of professors and of the subject domains where to create or suppress chairs -, but also concerning process, where (as the Neuchâtel and USI cases clearly display) this is a central matter of negotiation and share of functions between central administration and academics; in fact most conflicts on strategies emerged around chair planning. This can be related to some shared principles of human resources management in the three considered institutions: despite differences in legal settings - USI and SUPSI having a completely private contractual system, while in Neuchâtel professors are hired under public legislation -, in all three case studies professors de facto have a lifelong tenure and hence appointments of chairs imply a long-term commitment not only concerning subject areas, but also persons. In this context, strategy can be implemented through selective appointments in domains to be reinforced - an easier task in the two fastexpanding institutions than in Neuchâtel -, through non renewal of chairs on leaving for retirement or other position or, as for micro-technique in Neuchâtel, through transfer of chairs to other institutions.

\subsection{Handling a changing environment and achieving legitimacy}

It is relevant at this stage to inquire to which extent the characteristics of these strategies helped these organizations to master their relationships with the environment and to find a suitable position within the national system.

USI can be considered as a success case in developing an original model conforming with the basic elements of what is considered a Swiss university and thus achieved national legitimacy at the political and academic level, but at the same time introduced elements of novelty for example in a distinctive mix of 
disciplines, in developing new domains of research with limited tradition in Switzerland and in an internal organization nearer to private companies than to traditional Swiss universities. It also balanced successfully the need for international reputation with a strong regional role, given the fact that the hosting Canton provides most of the financial means. This success is reflected in the steady growth during the last ten years, in terms of students, staff, research funds and output and budget.

Our study shows that the ability of developing a coherent pattern of action across time was critical for a very small institution to achieve these results, to overcome resistance from the established powers and to survive to unsuccessful experiments without disruptions; institutional autonomy was important in this respect to avoid external interventions and to provide flexibility, but at the same time the integration of Cantonal authorities and of representatives of the Swiss academic community in the university council allowed for sharing strategic decisions with the most important external stakeholders.

USI faced a single challenge - building a new university - and this is likely to explain why continuity in the core element of the strategy was a successful recipe. At the contrary, the University of applied sciences was faced with two largely contrasting challenges: firstly, how to implement the new federal mandate and, especially, to develop applied research throughout the whole institution; secondly, how to manage the merger process - developing a shared identity, rule system and strategy - and how to adapt the organizational structure in an expanding structure under perpetual reorganization.

Each of the two strategies we identified were able to successfully respond to one of these challenges at the expenses of a lower success in the other one (less dynamics in the development of research in the first phase, an increasingly complexity of internal decision-making processes in the second phase). The key for organizational success was largely in the ability to identify correctly the need for a change in strategy, but also to implement it thanks to a radical and rapid internal reorganization. Two elements were conductive to this process: the arrival of a new director and the freedom to decide autonomously the internal governance structure. When external challenges are so conflicting that no single strategy can provide a valid answer, creating conditions for strategic change would appear more important than long-term coherence.

Finally, Neuchâtel displays the case of a small institution in a severely threatened position - by the mid nineties the Canton gave clear signals that it would not provide sufficient financial means to support a comprehensive institution with a cost-intensive science faculty - , which was not able to implement a coherent strategy and where internal conflicts jeopardized attempts of change; the Canton repeatedly intervened to modify the internal structure, but was never able to design a governance allowing a balance between centralization and subscription. Eventually, when internal conflicts became too strong and visible, the Canton assumed itself the strategic power and imposed its vision of a regional oriented university focused on education and on less cost-intensive research domains like plant biology; in the Swiss university system the winner was the federal institute of technology in Lausanne which was able to integrate the 
prestigious micro-technique department. In this case, environmental challenges exceeded the strategic capability of the organization, while its main stakeholder was not willing to grant sufficient time for internal change and this led to organizational disruption.

\section{Conclusion: university strategies reconsidered}

We organize our conclusions according to the three main questions of the paper, namely to empirically investigate the nature of strategies, to discuss the relationship between strategies and governance and, finally, to look to their impact on the portfolio of activities and the position in the national higher education system.

Firstly, our empirical findings show that in all three cases there are concrete attempts of creating organizational coherence through strategy and consistent patterns emerge across time; moreover, these patterns go beyond the simple continuation of past trends, but represent true attempts to actively steer organizational behavior. This is not always apparent in the formal strategic plans since higher education institutions are too complex and decentralized to allow for detailed planning. Because of their rigidity in organizations where formal decision-making processes tend be slow, strategic plans can reasonably define the core objectives of a strategy, but implementation needs to be managed in a more informal and flexible way. In higher education institutions, strategies tend to emerge from bottom-up experiments, but those coherent with the overall organizational goals need to be integrated in the planning cycle and thus strategies cannot be purely adaptive. This integration and selection function is the central role of academic administrators rather than the development of top-down planning, as some of our case studies clearly display.

Secondly, in our three case studies strategic coherence critically depended on a governance structure able to balance between centralization of power and decision-making processes to one side, subscription and delegation to the academic understructure to the other side. Two of our case studies display the fragility of a strategy not endorsed by the understructure and its negative impact on the capability of the organization to innovate. Recipes on how to achieve this balance are however dependent on the specific features of the concerned organization, like size, activities and history; political authorities should then refrain to transfer recipes working in other institutions without carefully considering their context of application. However, good communication through formal and informal means between centre and understructure - in both directions - would seem a prerequisite for a working and accepted strategy.

Finally, the case studies show that for small HEls, which cannot profit from mass enrollments a coherent action is the only way to compete and try to steer their own trajectory - i.e. differentiate, when faced with competitors endowed with much larger power and resources. As one of our cases shows, when 
organizational coherent action is not possible the range of options available diminishes dramatically and the institution gets exposed to competitors or to direct intervention of political authorities.

Of course, these reflections can only to a very limited extent be supported by our three case studies, all of them being small institutions where the issue of finding a sustainable position was central. Nevertheless, we believe that these results demonstrate that also for HEl strategies are a relevant component of organizational action and show the interest of an empirical analysis, where the specific nature of university strategies and the differences between individual institutions are carefully examined.

\section{References}

\section{REFERENCES}

Amaral, A., Jones, G. A. and Karseth, B., editors. 2002. Governing Higher Education: National Perspectives on Institutional Governance. Dordrecht / Boston / London: Kluwer Academic Publishers.

Baldridge, J. 1971. Power and Conflict in the University: Research in the Sociology of Complex Organizations. New York: John Wiley.

Bingham, C. and Eisenhardt K. 2008. "Position, leverage and opportunity: a typology of strategic logics linking resources with competitive advantage." Managerial and Decision Economics 29: 241-56.

Bleiklie, I. 2008. Excellence and the Diversity of Higher Education Systems. Paper presented at the 21st Annual CHER Conference, 11-13 September 2008, Pavia.

Bonaccorsi, A. and Daraio, C. 2007a. "Theoretical perspectives on university strategy." Pp. 3-30 in Universities and Strategic Knowledge Creation. Specialization and Performance in Europe, edited by Bonaccorsi, A. and Daraio, C. Cheltenham: Edwar Elgar.

Bonaccorsi, A. and Daraio, C., editors. 2007b. Universities and Strategic Knowledge Creation. Specialization and Performance in Europe. Cheltenham: Edwar Elgar.

Bonaccorsi, A. and Daraio, C. 2007c. "Universities as strategic knowledge creators: some preliminary evidence." Pp. 31-81 in Universities and Strategic Knowledge Creation. Specialization and Performance in Europe, edited by Bonaccorsi, A. and Daraio, C. Cheltenham: Edwar Elgar.

Chaffee, E. E. 1985. "Three models of strategy." The Academy of Management Review 10:89-98.

Chandler, A. D. 1990. Strategy and Structure: Chapters in the History of the Industrial Enterprise. MIT Press.

Cohen, M. D. and March, J. G. 1974. Leadership and ambiguity: The American college president. Hightstown, New Jersey: McGraw-Hill Book Company.

Cohen, M. D., March, J. G. and Olsen, J. P. 1972. "A garbage can model of organizational choice." Administrative Science Quarterly 17:1-25. 
Dill, D. 1996. "Academic Planning and Organizational Design: Lessons from Leading American Universities." Higher Education Quarterly 50: 35-53.

Duderstadt, J. J. 2000. A University for the 21st Century. The University of Michigan Press.

Ferlie, E., Musselin, C. and Andresani, G. 2008. "The steering of higher education systems: a public management perspective." Higher Education 56:325-348.

Fumasoli, T. 2007. Governance in Swiss Universities. A Comparative Analysis through Cantonal and Federal Laws. Draft Paper. Università della Svizzera italiana, Lugano: .

Fumasoli, T. 2008a. "Governance in Swiss Universities. A comparative Analysis through Cantonal and Federal laws.":Paper presented at the 5th EUREDOCS Conference, Modernising European higher education: priorities, ideas and challenges, Porto, 23-25 May 2008.

Fumasoli, T. 2008b. Official strategies of Swiss universities. A documentary analysis. Lugano: Università della Svizzera Italiana.

Gimeno, J. 2002. "The performance effects of unintended and purposive multimarket contact." Managerial and Decision Economics 23:209-224.

Ginsberg, A. 1984. "Operationalizing organizational strategy: toward an integrative framework." Academy of Management Review 9:548-557.

Gioia, D. A. and Thomas, J. B. 1996. "Identity, image and issue interpretation: sensemaking during strategic change in academia." Administrative Science Quarterly 41:370-403.

Hambrick, D. and Friedrickson, W. 2001. "Are you sure you have a strategy?" Academy of Management Executive 15/4: 48-59.

Hardy, C. 1991. "Configuration and strategy making in universities: broadening the scope." The Journal of Higher Education 62:363*393.

Jarzabkowski, P. 2008. "Shaping strategy as a structuration process." Academy of Management Journal 51/4: 621-50.

Keller, G. 1983. Academic Strategy. The Management Revolution in American Higher Education. London: The John Hopkins University Press.

Kotler, P. and Murphy, P. E. 1981. "Strategic planning for higher education." The Journal of Higher Education 52:470-489.

Krücken, G. and Meier, F. 2006. "Turning the University into an Organizational Actor." Pp. 209-240 in Globalization and Organization. World Society and Organizational Change. edited by Drori, G. S., Meyer, J. W. and Hwang, H. Oxford University Press.

Lepori, B. 2007. "Patterns of diversity in the Swiss higher education system." Pp. 209-240 in Universities and Strategic Knowledge Creation. Specialization and Performance in Europe, edited by Bonaccorsi, A. and Daraio, C. Cheltenham: Edwar Elgar.

Lepori, B. and Fumasoli, T. 2008. "Swiss university configuration: changes and future scenarios.":Paper presented at the CHER Conference, Pavia, 11-13 September 2008. 
Leslie, D. W. 1996. "'Strategic Governance": The Wrong Questions?" The Review of Higher Education 20: 101-112.

Lovas, B. and S. Ghoshal. 2000. Strategy as guided evolution. Strategic Management, 21/9, 875-896

Maassen, P. and Potman, H. 1990. "Strategic Decision Making in Higher Education: An Analysis of the New Planning System in Dutch Higher Education." Higher Education 20: 393-410.

MacCrimmon, K. R. 1993. "Do firm strategies exist?" Strategic Management Journal 14:113-130.

Mintzberg, H. 1979. The Structuring of Organizations. Englewood Cliffs, NJ: Prentice-Hall.

Mintzberg, H. 1994. The Rise and Fall of Strategic Planning. Free Press and Prentice-Hall International.

Mintzberg, H. and Waters, J. A. 1985. "Of strategies, deliberate and emergent." Strategic Management Journal 6:257-272.

Musselin, C. 2007. "Are Universities Specific Organisations?" Pp. 63-84 in Towards a Multiversity? Universities between Global Trends and National Traditions, edited by Krücken, G., Kosmützky, A. and Torka, M. Bielefeld: transcript.

Oliver, C. 1991. "Strategic responses to institutional processes." The Academy of Management Review 16:145-179.

Porter, M. E. 1980. Competitive Strategy: Techniques for Analyzing Industries and Competitors. New York: The Free Press.

Porter, M. E. 1996. "What is strategy?" Harvard Business Review November-December: 59-79.

Rivkin, J. 2001. "Reproducing knowledge: replication without imitation at moderate complexity." Organization Science 12: 274-293.

Sabatier, P. 1987. "Knowledge, Policy-Oriented Learning, and Policy Change: An Advocacy Coalition Framework." Science Communication 8: 649-92.

Salancik, G. R. and Pfeffer, J. 1974. "The Bases and Use of Power in Organizational Decision Making: The Case of a University." Administrative Science Quarterly 19 (4):453-473.

Scott, W. R. 2003. Organizations. Rational, Natural and Open Systems. Upper Saddle River, New Jersey: Prentice Hall, Pearson Education International.

Siggelkov, N. 2002. "Evolution toward fit." Administrative Science Quarterly 47: 125-59.

Steiner, G. 1979. Strategic planning. New York: Free Press.

Weick, K. E. 1976. "Educational organizations as loosely coupled systems." Administrative Science Quarterly 21:1-19.

Weick, K. E. 1979. The social psychology of organizing. New York: Random House. 